\title{
LOW-ENERGY METASTABLE AUTOIONIZING STATES IN NITROGEN, OXYGEN, AND NEON (*)
}

\author{
K. O. GROENEVELD, G. NOLTE $\left({ }^{* *}\right)$ and S. SCHUMANN \\ Institut für Kernphysik der Universität Frankfurt/M., Germany
}

(Reçu le 7 octobre 1975, accepté le 5 novembre 1975)

\begin{abstract}
Résumé. - On observe un triple pic dans les spectres d'énergie électroniques utilisés pour déterminer les durées de vie de l'état métastable à trois électrons (1s $2 s \quad p){ }^{4} \mathrm{P}_{5 / 2}$ dans l'azote, l'oxygène et le néon. Le pic qui a la plus haute énergie de transition correspond à la décroissance de l'état ${ }^{4} \mathbf{P}_{5 / 2}$. On attribue une seconde transition à la décroissance de l'état $\left(1 \mathrm{~s} 2 \mathrm{~s}^{2}\right)^{2} \mathrm{~S}_{1 / 2}$. La durée de vie relativement longue de cet état non métastable peut être due à des effets de cascade.
\end{abstract}

Abstract. - In the electron energy spectra used to determine life-times of the metastable three electron (1s 2s 2p) ${ }^{4} \mathrm{P}_{5 / 2}$-state in nitrogen, oxygen, and neon a triple peak structure is observed. The peak with the highest transition energy corresponds to the decay of the ${ }^{4} \mathrm{P}_{5 / 2}$-state. A second transition is attributed to the decay of the $\left(1 \mathrm{~s} 2 \mathrm{~s}^{2}\right)^{2} \mathrm{~S}_{1 / 2}$-state. The relatively long life-time of this non-metastable state may be due to cascading effects.

The decay of the metastable three electron (1s 2s 2p) ${ }^{4} \mathrm{P}_{5 / 2}$-state in the isoelectronic series from $\mathrm{He}^{-}$to $\mathrm{Ar}^{15+}$ has attracted much interest recently (see e.g. ref. [1] and references quoted there). In a previous publication [2] we reported on the study of life-times of this state in nitrogen, oxygen and neon. The present work will deal with metastable autoionizing states which yield energies below those from the (1s 2s 2p) ${ }^{4} \mathrm{P}_{5 / 2}$-state.

With a coupled time of flight beam-foil technique we studied autoionization electron energy spectra of foil-excited nitrogen at $4 \mathrm{MeV}$, oxygen at $5 \mathrm{MeV}$, and neon $10 \mathrm{MeV}$ incident energies with an electrostatic coaxial cylinder electron spectrometer [3]. The electron energy spectra were measured as a function of the time of flight between excitation of the projectiles in the target foil and deexcitation in the focus of the spectrometer; for details of the experimental set-up see references $[4,5]$.

Figure 1 shows the $\mathrm{N}, \mathrm{O}$, and $\mathrm{Ne}$ electron energy spectra after a time of flight of $12 \mathrm{~ns}$. The triple peak structure observed here has not been reported earlier.

This triplet structure is observed under different experimental conditions always after times of flight of more than $5 \mathrm{~ns}$.

Although the experimental energy resolution is not

$\left(^{*}\right)$ Work supported in part by Bundesministerium für Forschung und Technologie, Bonn/Germany.

(**) Present address : Physikalisches Institut Universität Heidelberg, Germany.

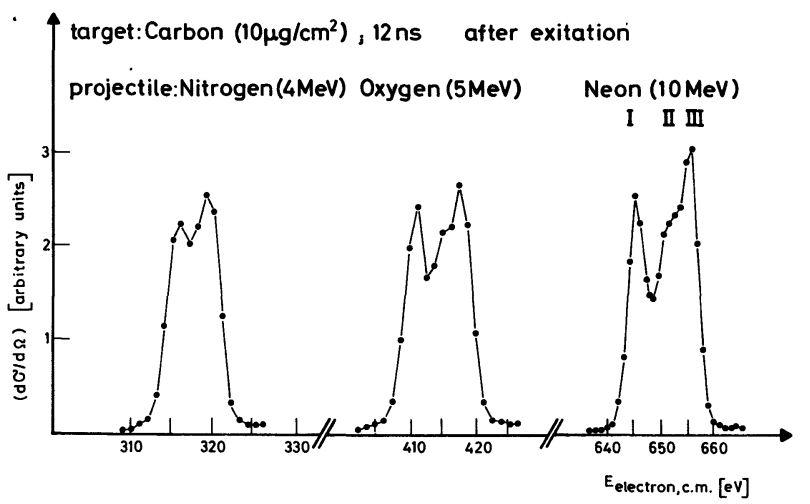

Fig. 1. - Electron energy spectra from the decay of beam-foil excited metastable states in nitrogen (left), oxygen (middle) and neon (right) after a time of flight of $12 \mathrm{~ns}$.

sufficient to separate peak II and peak III in nitrogen (Fig. 1); in oxygen and neon, however, more than two peaks are clearly seen. To exclude instrumental effects causing the observed triplet structure it should be noted that :

1) the measured life-times for the three peaks are different (see Table I) and

2) the observed lines are discrete in contrast to what would be expected from scattering effects (e.g. aperture scattering).

A comparison of the experimental transition energies and life-times with theoretical results [2], [5, 6] (Table I) shows that peak III can be attributed to the decay of the (1s $2 s 2 p){ }^{4} \mathrm{P}_{5 / 2}$-state to the two 
TABLE I

Experimental and theoretical transition energies $E$ and life-times $t$

$\begin{array}{lcccc}\text { Peak } & E_{\exp }(\mathrm{eV}) & E_{\text {theor }}(\mathrm{eV}) & t_{\exp }(\mathrm{ns}) & t_{\text {theor }}(\mathrm{ns}) \\ - & - & - & 30.9 \pm 7 & \\ \mathrm{~N}(\mathrm{I}) & 315 \pm 2 & & 30.9 \pm 7 & \\ \mathrm{~N}(\mathrm{II}) & & & & \\ \mathrm{N}(\mathrm{III}) & 319 \pm 2 & 317.1\left(^{\mathrm{b}}\right) & 53.6 \pm 13 & 42.7\left(^{\mathrm{b}}\right) \\ \mathrm{O}(\mathrm{I}) & 411 \pm 2 & & 19.9 \pm 3 & \\ \mathrm{O} \text { (II) } & 415 \pm 2 & & 20.4 \pm 3 & \\ \mathrm{O} \text { (III) } & 418 \pm 2 & 417.7\left(^{\mathrm{b}}\right) & 20.0 \pm 3 & 23.1\left(^{\mathrm{b}}\right) \\ \mathrm{Ne} \text { (I) } & 646 \pm 2 & & 16.8 \pm 2 & \\ \mathrm{Ne}(\mathrm{II}) & 652 \pm 2 & 652.7\left(^{\mathrm{a}}\right) & 11.5 \pm 1.5 & \\ \mathrm{Ne}(\mathrm{III}) & 656 \pm 2 & 656.3\left(^{\mathrm{a}}\right) & 10.4 \pm 1.5 & 8.4\left(^{\mathrm{b}}\right)\end{array}$

(a) Reference [4].

(b) Reference [6].

electron $\left(1 \mathrm{~s}^{2}\right){ }^{1} \mathrm{~S}_{0}$-groundstate as has been reported [2]. Theoretical transition energies allow only one possibility for a lower transition energy than the decay energy of the ${ }^{4} \mathrm{P}_{5 / 2}$-state and this is the decay energy of the $\left(1 \mathrm{~s} 2 \mathrm{~s}^{2}\right)^{2} \mathrm{~S}_{1 / 2}$-state. For Ne this is in excellent agreement with peak II (Table I). However, this state decays via Coulomb interaction and is not metastable in contrast to the experimental findings. Furthermore, there is no theoretical transition energy corresponding to the lowest observed line (peak I).

Two possibilities come to mind to explain, at least qualitatively, the discrepancy for peak II : 1) metastable higher energy state(s) feed the (1s $\left.2 \mathrm{~s}^{2}\right)^{2} \mathrm{~S}_{1 / 2}$-state (cascading) and 2) a spectator electron orbiting as additional fourth electron with high principal quantum numbers $\left({ }^{1}\right)$. Further investigation is needed to elucidate this discrepancy.

Considering these results we note that the errors involved in the experimentally observed life-times of the metastable (1s $2 \mathrm{~s} 2 \mathrm{p}){ }^{4} \mathrm{P}_{5 / 2}$-state in nitrogen, oxygen and neon [2] are large; deviations from calculated life-times [6] are therefore not significant in this experiment and may not be interpreted yet as indication of such phenomena as : electron correlation or intermediate coupling [6].

( $\left.{ }^{1}\right)$ Sellin, I. A., ORNL, private communication.

\section{References}

[1] Martinson, I., Gaupp, A., Phy's. Rep. 15C (1974) 113.

[2] Groeneveld, K. O., Mann, R., Nolte, G., Schumann, S., SPOHR, R., Phys. Lett. 54A (1975) 335.

[3] Dietz, E., Groeneveld, K. O., Spohr, R., Staudte, R., Nucl. Instrum. Methods 105 (1972) 467.
[4] Groeneveld, K. O., Mann, R., Nolte, G., Schumann, S., SPOHR, R. and Fricke, B., Z. Phys. 274 (1975) 191.

[5] Haselton, H. H., Thoe, R. S., Mowat, J. R., Griffin, P. M., PegG, D. J., Sellin, I. A., Phys. Rev. A 11 (1975) 468.

[6] Cheng, K. T., Lin, C. P., Johnson, W. R., Phys. Lett. A 48 (1974) 437 , and private communications. 